\title{
It's Hard Work Being No One
}

\author{
J. Scott Jordan* \\ Department of Psychology, Director, Institute for Prospective Cognition, Illinois State University, Normal, IL, United States
}

Keywords: embodiment, Wild Systems Theory, self-sustaining systems, representation, naturalism, self-model

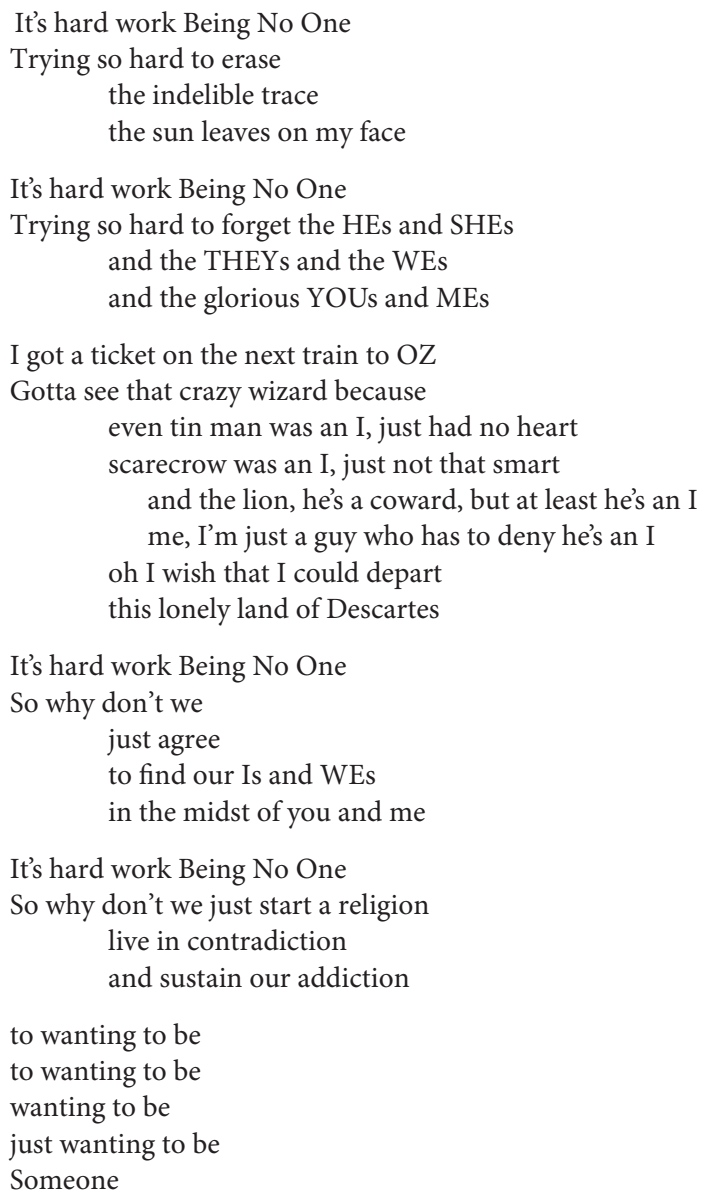

I wrote this song (It's Hard Work Being No One, Supplementary Audio 1) for Thomas Metzinger during the winter of 2006. We were part of a research team investigating Embodied Communication in Humans and Machines, organized by Ipke Wachsmuth and Guenther Knoblich. And while the song might seem a criticism of Thomas' self-model theory of subjectivity (SMTS-Metzinger, 2003), actually, it's a tribute to the most scientifically informed position on consciousness and the self, to date.

It's hard work Being No One. The song is also an Eric Idle-esque "wink-wink, nudge-nudge" at differences that exist between SMTS and Wild Systems Theory (WST-Jordan and Ghin, 2006; Jordan, 2013). WST follows the lead of Odum (1988) and conceptualizes living systems as multi-scale nestings of self-sustaining, energy-transformation systems. Such systems are self-sustaining because their work (i.e., energy expenditures) produces products (e.g., catalysts) that feedback into and, ultimately sustain the work. This principle has been discovered at 
many levels of scale, including chemical systems (autocatalysisKauffman, 1995), the single-cell (autopoiesis-Maturana and Varela, 1980), neural networks (the cell assembly-Hebb, 1949), behavior (reinforcement theory-Skinner, 1974), and ecologies in general (Odum, 1988).

The indelible trace the sun leaves on $\boldsymbol{m y}$ face. Self-sustaining systems persist because their work generates and maintains permeable borders. In the case of a neuron, the border is a lipid bilayer. In the case of a conscious self, the border is a phenomenal self-model (PSM-Metzinger, 2003), that entails transparent, representational content of a, “... preattentive self-world border" (p. 307).

While SMTS and WST agree the generation and sustainment of a PSM border affords the existence of "mineness," their differing approaches to "representation" lead to divergent accounts of why "mineness" entails the conscious sense of being someone.

The lonely land of Descartes. Theories of how representations acquire their "aboutness" are rather varied (Dretske, 1981; Fodor, 1981; Anderson and Rosenberg, 2008), perhaps reflecting the difficulty of grounding the existence of meaning (i.e., "aboutness") in the confines of contemporary naturalism, where "... the harshness of naturalist metaphysics exactly consists in the point that nothing has intrinsic value" (Metzinger, 2017, p. 18).

WST bypasses naturalism's "grounding problem" (Harnad, 1990) because self-sustaining systems emerge from the energy transformation contexts (i.e., ecologies) in which they sustain themselves (Jordan and Ghin, 2006). As a result, they are naturally and necessarily about these contexts. Said another way, self-sustaining systems (i.e., organisms) constitute embodiments of context, or embodied aboutness. They are aspects of reality (i.e., context) whose activity (i.e., work) gives rise to and sustains a border between the system and the context in which it sustains itself.

According to the notion of embodied context, our neuromuscular architecture can be conceptualized as a multiscale embodiment (i.e., representation) of the constraints that have to be addressed to propel a mass, as a whole, through a gravity field. Given that muscles, bones, and brains constitute embodiments of context, WST argues they entail what traditional theories of representation refer to as representational content (i.e., “aboutness"). They are embodiments of context that are "about" the contexts they embody.

Given this embodied-context approach to "aboutness" versus the traditional representational-content approach, WST proposes that subjectivity, phenomenology, and consciousness constitute forms of embodied aboutness that evolved from lower forms of embodied aboutness such as single- and multi-cell organisms. In

\section{REFERENCES}

Anderson, M. L., and Rosenberg, G. (2008). Content and action: the guidance theory of representation. J. Mind Behav. 29, 55-86.

Dretske, F. (1981). Knowledge and the Flow of Information. Cambridge, MA: The MIT Press.

Fodor, J. (1981). Representations: Philosophical Essays on the Foundations of Cognitive Science. Cambridge, MA: The MIT Press. the case of a conscious self, WST agrees with the SMTS assertion that a PSM, "...generates a pre-attentive self-world border..." (p. 307). According to WST however, the "aboutness" isn't so much an informational aspect of a physical brain, as it is the contextual emergence of a globally available pattern of neural dynamics whose activity (i.e., "work") generates and sustains a coherent activation border between itself and the brain as a whole (i.e., activation and inhibition patterns across a large-scale, multimodule network). Consistent with SMTS, WST asserts that the "aboutness" of a conscious self comes to be as a particular pattern of self-sustaining neural dynamics emerges within the context of the type of representational (i.e., "aboutness") context specified by SMTS. Thus, in the end, it seems the biggest difference between SMTS and WST is their ontology, not their science. SMTS begins with a physical-driven naturalism, while WST begins something a bit more Spinozan and conceptualizes all phenomena as embodiments of context, what Spinoza referred to as finitudes.

The glorious YOUs and MEs. It's glorious being someone. And whether it's an illusion in an inherently meaningless, physical reality, or a perpetually arduous journey through a reality constituted of ubiquitous aboutness, coherence demands that Thomas' SMTS be part of the content entailed in my own selfmodel of the science of consciousness. Thanks, Thomas, for your hard work. I am a more coherent someone because of it.

\section{AUTHOR CONTRIBUTIONS}

The author confirms being the sole contributor of this work and has approved it for publication.

\section{ACKNOWLEDGMENTS}

I would like to thank the editors and their reviewers for their extremely valuable comments on this manuscript. I'd also like to thank Ipke Wachsmuth and Guenther Knoblich for inviting me to participate in the research group where I had the opportunity to work with Thomas. Finally, special thanks to Jennifer Windt for allowing me to include a recording of the song, and to the musicians at Illinois State University who performed it with me and helped record it: Isaac Soares, Miles Bohlman, Sam Tedeschi, and Derek Zimmerman. See Supplementary Data Sheet 1 for detailed acknowledgements.

\section{SUPPLEMENTARY MATERIAL}

The Supplementary Material for this article can be found online at: https://www.frontiersin.org/articles/10.3389/fpsyg. 2018.02632/full\#supplementary-material

Harnad, S. (1990). The symbol grounding problem. Physica D Nonlinear Phenomena, 42, 335-346.

Hebb, D. O. (1949). The Organization of Behavior: A Neuropsychological Theory. New York, NY: Wiley.

Jordan, J. S. (2013). The wild ways of conscious will: What we do, how we do it, and why it has meaning. Front. Psychol. 4:574. doi: 10.3389/fpsyg.2013.00574

Jordan, J. S., and Ghin, M. (2006). (Proto-) consciousness as a contextuallyemergent property of self-sustaining systems. Mind Matter 4, 45-68. 
Kauffman, S. (1995). At Home in the Universe. New York, NY: Oxford University Press.

Maturana, H. R., and Varela, F. J. (1980). "Problems in the neurophysiology of cognition," in Autopoiesis and Cognition (Dordrecht: Springer; D. Reidel Publishing Company), 41-47.

Metzinger, T. (2003). Being No One. The Self-Model Theory of Subjectivity. Cambridge, MA: MIT Press.

Metzinger, T. K. (2017). "The problem of mental action: Predictive control without sensory sheets," in Philosophy and Predictive Processing: 19, eds T. Metzinger and W. Wiese (Frankfurt am Main: MIND Group), 1-26.

Odum, H. T. (1988). Self-organization, transformity, and information, Science 242, 132-139.
Skinner, B. F. (1974). About Behaviorism. New York, NY: Vintage Books.

Conflict of Interest Statement: The author declares that the research was conducted in the absence of any commercial or financial relationships that could be construed as a potential conflict of interest.

Copyright (c) 2018 Jordan. This is an open-access article distributed under the terms of the Creative Commons Attribution License (CC BY). The use, distribution or reproduction in other forums is permitted, provided the original author(s) and the copyright owner(s) are credited and that the original publication in this journal is cited, in accordance with accepted academic practice. No use, distribution or reproduction is permitted which does not comply with these terms. 